\title{
Correlation of the Rates of Solvolysis of Isopropyl Fluoroformate Using the Extended Grunwald-Winstein Equation
}

\author{
So Hee Lee, Chan Joo Rhu, Jin Burm Kyong, Dong Kook Kim, and Dennis N. Kevill ${ }^{\dagger}$ \\ Department of Chemistry and Applied Chemistry Hanvang Cniversity, Ansan, Gveonggi 426-791, Korea \\ E-mail: jbhonghthanang ack kr \\ ${ }^{\dagger}$ Department of Chemistry and Biochemistry, Northern Ihinois Lniversitv, Dekalb, Ilinois 60115-2862, U.S.A. \\ Received Febriary 5, 2007
}

\begin{abstract}
The specific rates of solvolysis of isopropyl fluorofonnate are well correlated using the extended GnunwaldWinstein equation. with a sensitivity $(l)$ to changes in solvent nucleophilicity $\left(K_{\mathrm{T}}\right)$ and a sensitivity $(m)$ to changes in solvent ionizing power $\left(F_{C)}\right)$. The sensitivities $(t=1.59 \pm 0.16$ and $m=0.80 \pm 0.06)$ toward changes in solvent nucleophilicity and solvent ionizing power. and the $k_{\mathrm{F}} / k_{\mathrm{cl}}$ values are very similar to those for solvoly ses of n-octyl fluorofonnate. suggesting that the addition step of an addition-elimination mechanism is rate-determining. For methanolysis a solvent deuterium isotope effect of 2.53 is compatible with the incorporation of general-base catalysis into the substitution process. The large negative values for the entropies of activation are consistent with the bimolecular nature of the proposed rate-detennining step. These observations are also compared with those previously reported for the corresponding chlorofonnate and fluoroformate esters.
\end{abstract}

Key Words : Isopropyl fluoroformate, Addition-elimination, Grunwald-Winstein equation

\section{Introduction}

The extended Grunwald-Winstein equation (eqn. 1) has proven extremely valuable in studies of the mechanism of solvolysis reaction. ${ }^{1.2}$ In eqn. (1). $k$ and $k_{0}$ are the specific rates of solvoly sis of a

$$
\log \left(k / k_{0}\right)=\mid N_{\mathrm{T}}-m Y_{\mathrm{Cl}}+c
$$

substrate RX in a given solvent and in the standard solvent ( $80 \%$ ethanol), respectively: / represents the sensitivity of the solvolysis to changes in solvent nucleophilicity $N_{\mathrm{T}}=3$ represents the sensitivity of the solvolysis to changes in solvent ionizing power $Y_{C:}:^{4.5} c$ represents a constant (residual) term. Scales of solvent nucleophilicity and of solvent ionizing power are available and. by measuring $k$ and $k_{0}$. one can carry out a mathematical analysis to obtain the $l$ and $m$ values. For an ionization reaction without nucleophilic assistance. $l$ will be zero and $m$ close to unity. and. for a reaction proceeding with extensive nucleophilic assistance. the / value will be in the region of 1.6 to 2.0 and the $m$ value in the region below 0..$^{5(d) \text { (d) }) .6}$ Accordingly determination of these values will be a valuable source of information concerning the structure of the transition state for these solvoly'ses.

The simplest secondary alkyl group. isopropyl chloroformate ${ }^{6}$ leads to solvolyses which continue to show the two competing reaction channels. In this case an ionization pathway dominates over a wide range of solvents and only in the more nucleophilic and least ionizing solvents is the addition-elimination pathway dominant (Scheme 1).

The ionization pathway with solvolysis-decomposition is the only one operating for solvoly ses of l-adamantyl chloroformate ${ }^{7.8}$ Loss of carbon dioxide leads to the relatively stable 1-adamanty l cation. which can be captured by simul-

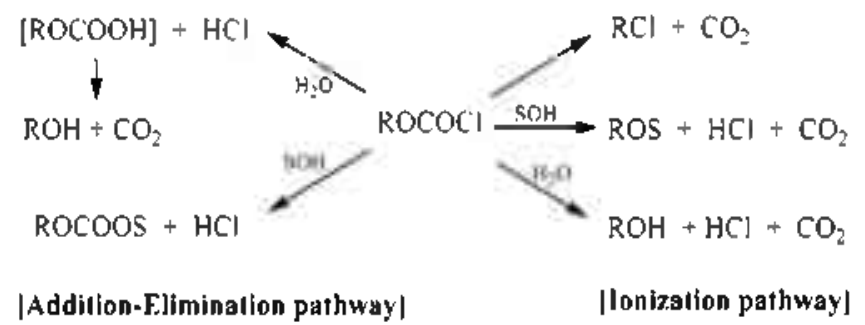

Scheme 1

taneously formed chloride ion or solvent. The corresponding 1-adamantyl fluorofonnate ${ }^{9}$ showed a very much reduced tendency toward ionization and only in solvents of high ionizing power and low nucleophilicity dose the behavior parallel that of the chloroformate. In other solvents. the predominant pathway involves addition-elimination.

A comparison of leaving group effects on the rates of solvolysis of chloroformate and fluoroformate esters might provide useful information about the reaction mechanisms. ${ }^{\text {ta }}$ For a recent report concerning the solvolyses of the $n$-octy $1^{13}$ and benzyl fluoroformate. ${ }^{12}$ the addition-elimination pathway was observed over the full range of solvents and the $k_{\mathrm{k}} /$ $k_{C l}$ ratios were only slightly below or above unity.

In the present paper. we report on the overall specific rates for solvolysis of isopropyl fluorofomate in a variety of pure and binary solvents and these analyses are then combined with a consideration of leaving group effects to arrive at a reasonable mechanism. In addition to the application of the extended Grunwald-Winstein equation to the specific rates. the influence of temperature on the specific rate (for four solvents) allows enthalpies and entropies of activation to be calculated a measurement in methanol-d allows a determination of the solvent deuterium isotope effect. 
Table 1. Specific rates of solvoly sis of isopropvl fluorofornate in a variety of pure and mixed solvents at $40.0^{\circ} \mathrm{C}$ and the $\mathrm{N}_{\mathrm{T}}$ and $\mathrm{I}_{\mathrm{Cl}}$ values for the solvents, and the specific rate ratio relative to isopropyl chlorofonmate $\left(k_{\mathrm{F}} / k_{\mathrm{Cl}}\right)$

\begin{tabular}{ccrrc}
\hline Solvent $(\%)^{a}$ & $10^{4} k, \mathrm{~s}^{-1}$ & \multicolumn{1}{c}{$\mathrm{N}_{\mathrm{T}}^{b}$} & \multicolumn{1}{c}{$\mathrm{Y}_{[]^{c}}$} & $k_{F} / k_{r-f}{ }^{d}$ \\
\hline $100 \mathrm{MeOH}$ & $0.595 \pm 0.021$ & 0.17 & -1.17 & 0.39 \\
$90 \mathrm{MeOH}$ & $5.40 \pm 0.22$ & -0.01 & -0.18 & 1.76 \\
$80 \mathrm{MeOH}$ & $11.8 \pm 0.01$ & -0.06 & 0.67 & 2.37 \\
$70 \mathrm{MeOH}$ & $18.4 \pm 0.1$ & -0.40 & 1.46 & 2.40 \\
$60 \mathrm{MeOH}$ & $25.2 \pm 0.4$ & -0.54 & 2.07 & 2.10 \\
$100 \mathrm{EtOH}$ & $0.0968 \pm 0.0030$ & 0.37 & -2.52 & 0.18 \\
$90 \mathrm{EtOH}$ & $1.82 \pm 0.02$ & 0.16 & -0.94 & 1.68 \\
$80 \mathrm{EtOH}$ & $3.93 \pm 0.21$ & 0.00 & 0.00 & 2.11 \\
$70 \mathrm{EtOH}$ & $6.40 \pm 0.07$ & -0.20 & 0.78 & 2.04 \\
$60 \mathrm{EtOH}$ & $9.16 \pm 0.04$ & -0.38 & 1.38 & 1.79 \\
$50 \mathrm{EtOH}$ & $14.9 \pm 1.0$ & -0.58 & 2.02 & 1.55 \\
$90 \mathrm{Me}-\mathrm{CO}$ & $0.0366 \pm 0.0034$ & -0.35 & -2.39 & 0.34 \\
$80 \mathrm{Me} \mathrm{CO}$ & $0.224 \pm 0.010$ & -0.37 & -0.83 & 0.53 \\
$70 \mathrm{Me}-\mathrm{CO}$ & $0.724 \pm 0.001$ & -0.42 & 0.17 & 0.61 \\
$60 \mathrm{Me} \mathrm{CO}$ & $1.84 \pm 0.08$ & -0.52 & 0.95 & 0.64 \\
$70 \mathrm{TFE}$ & $0.779 \pm 0.015$ & -1.98 & 2.96 & 0.067 \\
$50 \mathrm{TFE}$ & $2.66 \pm 0.41$ & -1.73 & 3.16 & - \\
$60 \mathrm{~T}-40 \mathrm{E}^{f}$ & $0.0915 \pm 0.0022$ & -0.94 & 0.63 & 0.12 \\
$40 \mathrm{~T}-60 \mathrm{E}^{f}$ & $0.141 \pm 0.013$ & -0.34 & -0.48 & 0.38 \\
$20 \mathrm{~T}-80 \mathrm{E}^{f}$ & $0.217 \pm 0.010$ & 0.08 & -1.42 & 0.69 \\
\hline
\end{tabular}

"Volume volume basis at $25.0{ }^{\circ} \mathrm{C}$. except for TFE- $\mathrm{H}_{2} \mathrm{O}$ mixtures which are on a weight weight basis. "Values from refs. 2. 3. "Values from rets. 4. $5{ }^{d}$ Values relative to those for the cortesponding solvolysis of isopropyl chlorofomate (values from ref. 6). "Value in $100^{\circ}$, MeOD of 0.235 $( \pm 0.02) \times 10^{-1} \mathrm{~s}^{-1}$. leading to a kleor $k_{\mathrm{NeO}}$ value of 2.53 , and the value of isopropyl chloroformate, $k_{\mathrm{H}_{2} \mathrm{O}} k_{\mathrm{D}} \mathrm{O}=1.25$. 'T-E represents TFEethanol mixtures.

\section{Results}

The specific rates of solvolysis of isopropyl fluoroformate at $40.0^{\circ} \mathrm{C}$ are reported in Table 1 . The solvents consisted of ethanol. methanol. binary mixtures of water with ethanol. methanol. 2.2.2-trifluoroethanol (TFE) acetone and three binary mixtures of TFE and ethanol. The $N_{\mathrm{T}}$ and $Y_{C l}$ values are also reported in Table 1 . together with the $k_{\mathrm{F}} / k_{\mathrm{Cl}}$ ratios. A determination was also made in methanol- $d$ (MeOD. footnote to Table 1).

For methanol. $80 \%$ methanol ethanol. $80 \%$ ethanol and $70 \%$ TFE. specific rates of solvolysis were determined at two and three additional temperatures. and these values. together with calculated enthalpies and entropies of activation. are reported in Table 2.

\section{Discussion}

A useful tool for quantitatively estimating the ratecontrolling influence of nucleophilic participation by solvent during a solvolysis reaction involves the application of the extended Gnuwald-Winstein equation (eq. 1) ${ }^{1.2}$ and compares the $/$ and $m$ values with those previously obtained for other haloformate esters. ${ }^{12}$

A consideration in terms of the simple Grumwald-Winstein equation [eqn. (l) without the $/ \mathrm{N}_{\mathrm{T}}$ term] to the specific rates of solvolysis in 20 representative solvents at $40.0^{\circ} \mathrm{C}$ leads to
Table 2. Specific rates for solvolysis of isopropyl fluoroformate at various temperatures and enthalpies and entropies of activation

\begin{tabular}{|c|c|c|c|c|}
\hline Solvent $(\%)^{2}$ & $T,{ }^{\circ} \mathrm{C}$ & $10^{4} k, s^{-1}$ & 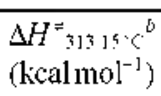 & $\begin{array}{c}\Delta S^{=} \text {:13 } 19 c^{b} \\
\left(\mathrm{cal} \mathrm{mol}^{-1} \mathrm{~K}^{-1}\right)\end{array}$ \\
\hline \multirow[t]{4}{*}{$100 \% \mathrm{MeOH}$} & 30.0 & $0.300 \pm 0.020$ & \multirow[t]{4}{*}{$11.7 \pm 0.7$} & \multirow[t]{4}{*}{$-40.8 \pm 2.5$} \\
\hline & 40.0 & $0.595 \pm 0.021$ & & \\
\hline & 45.0 & $0.842 \pm 0.062$ & & \\
\hline & 50.0 & $1.03 \pm 0.03$ & & \\
\hline \multirow[t]{3}{*}{$80 \% \mathrm{MeOH}$} & 30.0 & $6.94 \pm 0.71$ & \multirow[t]{3}{*}{$8.9 \pm 0.3$} & \multirow[t]{3}{*}{$-43.7 \pm 1.1$} \\
\hline & 40.0 & $11.8 \pm 0.01$ & & \\
\hline & 50.0 & $18.4 \pm 0.9$ & & \\
\hline \multirow[t]{4}{*}{$100 \%$ EtOH } & 30.0 & $0.0555 \pm 0.0052$ & \multirow{4}{*}{$11.3 \pm 0.9$} & \multirow[t]{4}{*}{$-45.5 \pm 3.4$} \\
\hline & 40.0 & $0.0968 \pm 0.0030$ & & \\
\hline & 45.0 & $0.150 \pm 0.006$ & & \\
\hline & 50.0 & $0.182 \pm 0.031$ & & \\
\hline \multirow[t]{4}{*}{$80 \% \mathrm{EtOH}$} & 30.0 & $2.25 \pm 0.30$ & \multirow[t]{4}{*}{$9.5 \pm 0.2$} & \multirow[t]{4}{*}{$-43.9 \pm 0.6$} \\
\hline & 40.0 & $3.93 \pm 0.21$ & & \\
\hline & 45.0 & $5.02 \pm 0.09$ & & \\
\hline & 50.0 & $6.36 \pm 0.11$ & & \\
\hline \multirow[t]{3}{*}{$70 \%$ TFE } & 30.0 & $0.360 \pm 0.050$ & \multirow[t]{3}{*}{$14.0 \pm 0.04$} & \multirow[t]{3}{*}{$-32.8 \pm 0.2$} \\
\hline & 40.0 & $0.779 \pm 0.015$ & & \\
\hline & 45.0 & $1.13 \pm 0.06$ & & \\
\hline
\end{tabular}

"Volume-volume basis at $25.0{ }^{\circ} \mathrm{C}$. "With associated standard error.

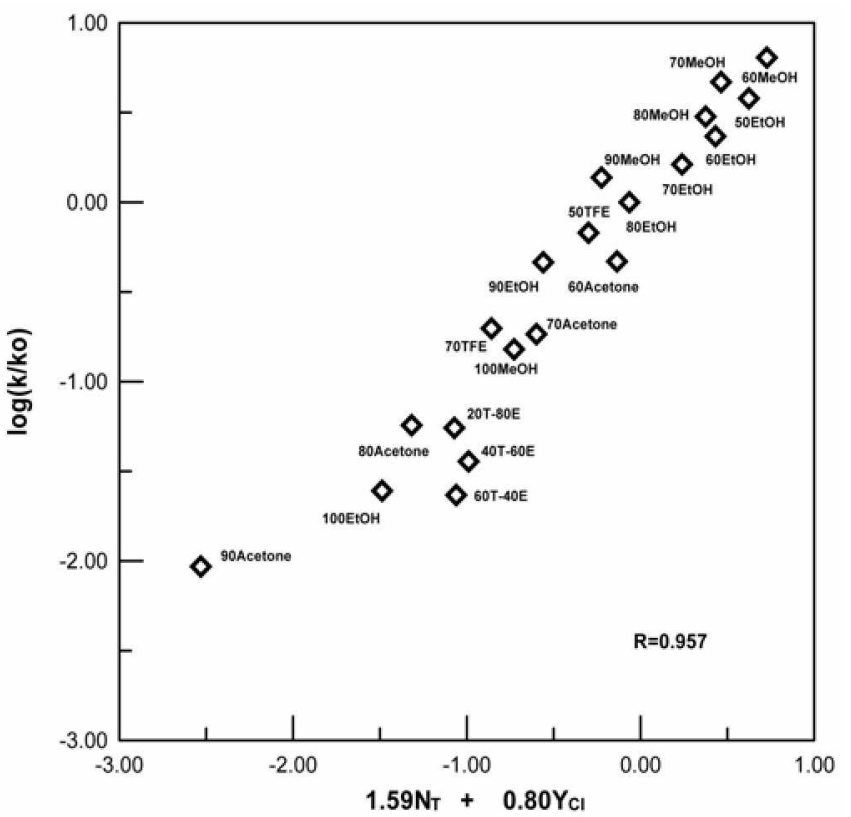

Figure 1. Plot of $\log \left(k / k_{0}\right)$ for solvolyses of isopropyl fluorotormate in all of the solvents at $40.0^{\circ} \mathrm{C}$ against $\left(1.59 \mathrm{~N}_{\mathrm{T}}+0.80 \mathrm{Y}_{\mathrm{Cl}}\right)$.

a poor correlation with value of 0.653 for the correlation coefficient (R). Again. An analysis using the extended Gnunwald-Winstein equation of the data for the specific rates of solvolysis of isopropyl fluoroformate leads to a good linear correlation with values of $1.59 \pm 0.16$ for $l .0 .80 \pm 0.06$ for $m .0 .06 \pm 0.08$ for $c$, and 0.957 for the correlation coefficient (F-test $=93$ ). Inspection of the plot corresponding to this correlation (Figure 1) showed that the three data points for solvolyses in TFE-ethanol mixtures lay below the best fit line. Recalculation with omission of these points led to 


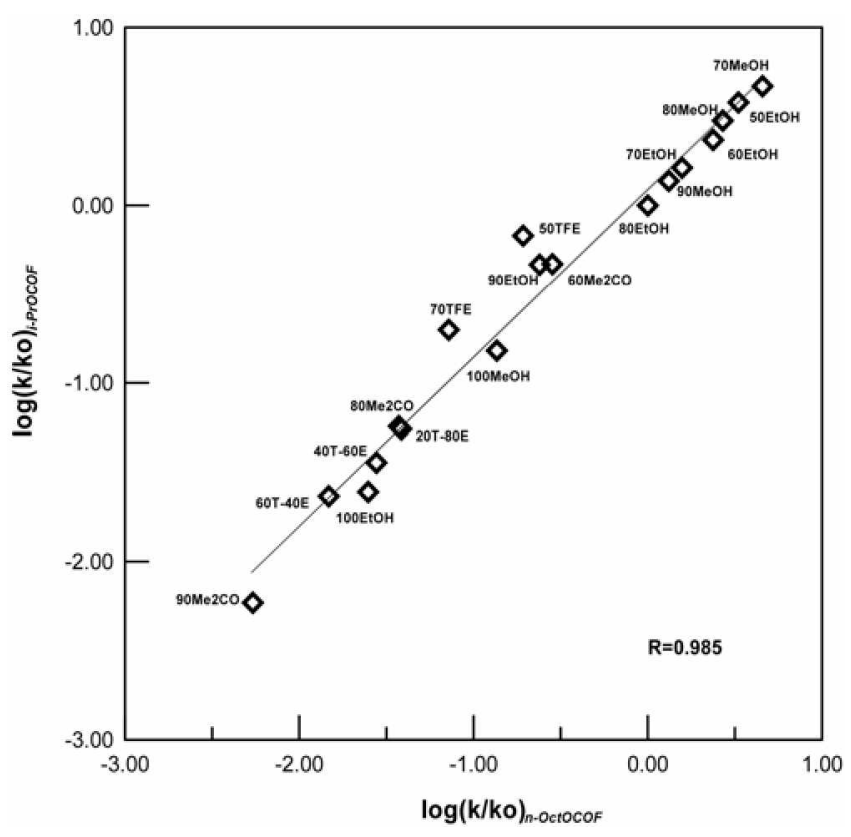

Figure 2. Plot of $\log \left(k / k_{0}\right)$ for solvolyses of isopropvl fluorotormate against $\log \left(k / k_{0}\right)$ for solvoly ses of $n$-octyl fluorofonnate in all

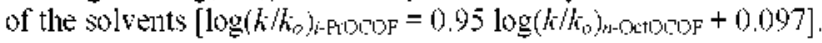

values of $1.44 \pm 0.12$ for $l .0 .74 \pm 0.04$ for $m,-0.03 \pm 0.06$ for $c$. and 0.978 for the correlation coefficient $(F-$ test $=152$ ). In earlier conrelations of other haloroformate esters. it was found that the data points for these solvent systems usually lay below the correlation line . $^{\text {sidi.13.1t }}$ This phenomenon was very recently discussed ${ }^{15}$ and it will not be considered again in this type. Correlations were carried out both with and without the TFE-ethanol data. The results of the correlation are presented in Figure 1 and reported in Table 3, together with the corresponding parameters obtained in the analyses of earlier studied substrates.

The sensitivity to changes in solvent nucleophilicity (I) will be close to unity; or even higher. if covalent attachment of solvent. functioning as a nuclephile. is involved in the slow step. The $/$ and $m$ values of 1.59 and 0.80 for the solvolysis of isopropyl fluoroformate. respectively: were very similar to previous values reported for bimolecular solvolyses of other chloroformate and fluoroformate esters. believed to solvolyze by an addition-elimination mechanism. with the addition being rate-determining

A plot of $\log \left(k k_{0}\right)$ for isopropyl fluoroformate against $\log \left(k k_{0}\right)$ for $n$-octyl fluorofommate ${ }^{11}$ is shown in Figure 2. This shows a good linear correlation $(R=0.985)$ in pure and mixed solvents. A good linear relationship for the solvolyses of isopropyl fluoroformate and $n$-octyl fluoroformate gives a strong evidence for a similarity model.

The $l$ and $m$ ratios have also been suggested as a useful mechanistic criterion and the values of Table 3 divide into two classes with values of 1.9 to 3.0 for those entries postulated to represent addition-elimination pathway and values below 0.8 for those believed to represent ionization pathway. ${ }^{6,7.13}$ For isopropyl fluoroformate. the value for the ratio of 2.0 is very similar to those previously observed for the solvolyses of $n$-octyl fluoroformate ${ }^{13}$ and benzoyl fluoride. ${ }^{16}$ which have been shown to solvolyze with the addition step of an addition-elimination pathway being rate deternining. The higher $m$-values for the solvolyses of fluoroformates. relative to chloroformates. may reflect the need for increased solvation of the developing negative charge on the carbonyl oxygen in the presence of the more electronegative fluorine attached at the carbonyl carbon.

The study of both the fluoroformate and chloroformate esters provides a route to mechanistic deductions in terms of the $k_{\mathrm{F}} / k_{\mathrm{Cl}}$ ratios. ${ }^{18}$ This is especially so when the attack is at an acyl carbon. When the carbon-halogen bond is broken in a nucleophilic displacement reaction. the specific rates of fluoro-derivative react appreciably slower than that for chloro-derivative as much as $10^{5}$ to $10^{7}$ times slower for a unimolecular ionization ${ }^{18,19}$ and some $10^{1}$ to $10^{2}$ times slower in bimolecular displacements at a saturated carbon..$^{21}$ The previous observations that. when a bimolecular attack at an acyl carbon is operative. fluoroformate and chloroformate esters solvolyze at very similar rates. frequently with the fluoroformate ester the faster. have been uniformly rationalized in terms of the addition step of an additionelimination mechanism being rate determining. The $k_{\mathrm{F}} / k_{\mathrm{C}}$ ?

Table 3. Coefficients from extended Grunwald-Winstein ${ }^{\sigma}$ correlations of the solvolyses of isopropvl fluoroformate and a comparison with corresponding values for the solvolyses of other chlorofonmate and fluoroformate esters and bencoyl fluoride

\begin{tabular}{|c|c|c|c|c|c|c|c|}
\hline Substrate & $\operatorname{Mech}^{b}$ & $n^{c}$ & $t^{7}$ & $m t^{d}$ & $c^{d}$ & $R^{e}$ & $H \mathrm{nt}$ \\
\hline $\mathrm{PhOCOCl}^{r}$ & $A-E$ & 21 & $1.68 \pm 0.10$ & $0.57 \pm 0.06$ & $0.12 \pm 0.41$ & 0.973 & 2.95 \\
\hline $\mathrm{MeOCOCl}^{g}$ & $A-E$ & 19 & $1.59 \pm 0.09$ & $0.58 \pm 0.05$ & $0.16 \pm 0.17$ & 0.977 & 2.74 \\
\hline EtOCOCl & A-E & 28 & $1.56 \pm 0.09$ & $0.55 \pm 0.03$ & $0.19 \pm 0.24$ & 0.967 & 2.84 \\
\hline EtoCOCl & I & 7 & $0.69 \pm 0.13$ & $0.82 \pm 0.16$ & $-2.40 \pm 0.27$ & 0.946 & 0.84 \\
\hline i-PTOCOCl' & I & 20 & $0.28 \pm 0.05$ & $0.52 \pm 0.03$ & $-0.12 \pm 0.05$ & 0.979 & 0.54 \\
\hline i-PTOCOF & A-E & 20 & $1.59 \pm 0.16$ & $0.80 \pm 0.06$ & $0.06 \pm 0.08$ & 0.957 & 1.99 \\
\hline OctocoF & $A-E$ & 23 & $1.80 \pm 0.13$ & $0.79 \pm 0.06$ & $0.13 \pm 0.34$ & 0.959 & 2.28 \\
\hline $\mathrm{C}_{6} \mathrm{H}_{5} \mathrm{COF}^{I}$ & $A-E$ & 41 & $1.58 \pm 0.09$ & $0.82 \pm 0.05$ & $-0.09 \pm 0.10$ & 0.953 & 1.93 \\
\hline $1-\mathrm{AdOCOCl}{ }^{\prime \prime}$ & I & 15 & -0 & $0.47 \pm 0.03$ & $0.03 \pm 0,05$ & 0.985 & -0 \\
\hline
\end{tabular}

"Using equation 1 . "Addition-elimination (A-E) and ionization (I). Number of solvent systems included in the correlation. ${ }^{\circ}$ With associated standard errors, those associated with the $c$ values being the standard errors of the estimate. "Correlation coefticient. Values from ref. 14. Ealues from ref. 17 . "Values from ref. 13. "Values from ref. 6 and the 24 solvents sistems studied, with omission of EtOH. $90{ }^{\circ}$ EtOH. MeOH. and $90^{\circ}$. $\mathrm{oMeOH}^{\circ}$ This study "Values from ret. 11. 'Values from ret. 16. ${ }^{n}$ Values trom ret. 7 . 
ratios for $S_{\mathrm{N}} \mathrm{I}$ solvolyses have been observed to be in the range of $10^{-6}$ (for $\mathrm{Ph}_{3} \mathrm{CX}^{21}$ ) to $10^{-7}$ (for $p-\mathrm{Me}_{2} \mathrm{NC}_{6} \mathrm{H}_{4} \mathrm{COX}^{19}$ ) and a low value of $1.3 \times 10^{-4}$ was also observed for acetyl halide solvoly'ses in $75 \%$ acetone. ${ }^{18}$ These values reflect an appreciable ground-state stabilization for the fluoride $e^{22}$ and the need to break a strong carbon-fluorine bond in the rate determining step. In contrast. if the addition step is ratedetermining. values of close to unity. reflecting a large electron deficiency at the carbonyl carbon of a haloformate incorporating fluorine. ${ }^{16}$ are frequently observed. This situation has recently been discussed in a consideration of n-octyl haloformate solvolyses. ${ }^{11}$ where $k_{\mathrm{F}} / k_{\mathrm{Cl}}$ specific rate ratios of 0.6 to 15 were observed. Due to the previous study of isopropyl chloroformate ${ }^{6}$ involving 19 of the 20 solvent compositions of the present study a wide range of $k_{\mathrm{F}} / k_{\mathrm{Cl}}$ values are available. For a meaningful consideration of this specific rate ratio at $40.0^{\circ} \mathrm{C}$ for solvolyses of isopropyl fluoroformate and isopropyl chloroformate (Table 1). it is important that the $k_{\mathrm{F}}$ and $k_{\mathrm{Cl}}$ values are for the same reaction pathway. The values for the ratio vary from a low of 0.2 in $100 \%$ ethanol (similar to the 0.6 for $n$-octyl haloformate) to a high of 2.1 in $80 \%$ ethanol (similar to the 2.9 for n-octyl haloformate in $80 \%$ acetone). The low value for $70 \% \mathrm{TFE}$ is to be expected because of the previously demonstrated dominance of an ionization pathway for solvolysis of the chloride in this solvent.

The solvent isotope effect has previously been studied for several solvolyses of chloroformate esters. In pure water the $k_{\mathrm{H}} \circ \mathrm{d} / k_{\mathrm{D} \Omega} \mathrm{O}$ ratio was in the range of 1.79 to 1.89 for methyl. ethyl. and phenyl chloroformate believed to react by the bimolecular mechanism. ${ }^{\hat{\imath}, \imath 4}$ The value for isopropyl chloroformate ${ }^{6}$ in the ionization range, was somewhat lower at 1.25 and the value for diphenylcarbamoyl chloride was lower again at 1.1..$^{t 3}$ Values in the range predicted for a bimolecular solvolysis have recently been reported for $k_{\mathrm{MeOH}} / k_{\mathrm{MeOD}}$ of $2.1-2.5$ for a series of substituted phenyl

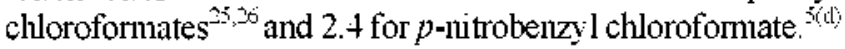
The value (footnote to Table 1) for methanoly sis of isopropyl fluoroformate of $k_{\mathrm{MeOH}} / k_{\mathrm{MeOD}}=2.53$ is of a magnitude usually taken to indicate that nucleophilic attack by a methanol molecule is assisted by general-base catalysis by a second methanol molecule. ${ }^{27, \Delta 8}$

For solvolyses in methanol. $80 \%$ methanol, ethanol, $80 \%$ ethanol. and $70 \% \mathrm{TFE}$, the values of the enthalpy and the entropy of activation for the solvolysis of isopropyl fluoroformate (Table 2) are 9.3 to $14.0 \mathrm{kcal} \mathrm{mol}^{-1}$ and -32.7 to $-45.5 \mathrm{cal} \mathrm{mol}^{-1} \mathrm{~K}^{-1}$, respectively. These values are consistent with the funding by Orlow of sumilar activation parameters for the ethanolyses of methyl, ethyl and isopropyl chloroformates and ethyl chlorothioformate. The very negative entropies of activation are consistent with the bimolecular reaction of the proposed rate-determining step.

\section{Conclusions}

The specific rates of solvoly ses of isopropyl fluoroformate give good correlation when analyzed using the extended
Grunwald-Winstein equation over the full range of solvents. The sensitivities to changes in $N_{\mathrm{T}}$ and $Y_{\mathrm{Cl}}(l=1.59$ and $m=$ 0.80 ) are very similar to those for several fluoroformate and chloroformate esters (Table 3), which have been shown to solvolyze with the addition step of an addition-elimination pathway being rate determining.

The $k_{\mathrm{F}} / k_{C l}$ values obtained in a comparison with the corresponding solvolysis of isopropyl fluoroformate are similar to those for solvolyses of $n$-octyl fluoroformate. consistent with a bimolecular addition-elimination mechanism. proceeding through a tetrahedral intermediate. Favoring the explanation in terms of alkyl variation is the observation ${ }^{3 i j}$ that the $k_{\mathrm{F}} / k_{\mathrm{Cl}}$ ratio for solvolyses of haloformate esters in $70 \%$ acetone at $30.1{ }^{\circ} \mathrm{C}$ decreases from methyl (7.16), ethyl (5.46) or $n$-propyl (4.95) to isopropyl (the $k_{\mathrm{F}} / k_{\mathrm{Cl}}$ ratio of isopropyl group in $70 \%$ acetone at $40.0^{\circ} \mathrm{C}$ is 0.61 ). suggesting that a value of lesser than unity would indeed be upon incorporation of a bulky secondary alky group. This trend could possibly be governed by increasing steric effects.

The solvent deuterium isotope effect value for methanolysis. $k_{\mathrm{MeOH}} / k_{\mathrm{MeOD}}=2.53$ is of a magnitude usually taken to indicate that nucleophilic attack by a methanol molecule is assisted by general-base catalysis by a second methanol molecule.

The entropies of activation $\left(-32.7\right.$ to $\left.-45.5 \mathrm{cal} \mathrm{mol}^{-1} \mathrm{~K}^{-1}\right)$ for isopropyl fluoroformate reaction. believed to involve rate-determining attack at acyl carbon, are considerably more negative than the values for reactions believed to proceed by an ionization pathway (the entropies of activation for 1adamantyl chloroformate are +3.3 to $+6.7 \mathrm{cal} \mathrm{mol}^{-1} \mathrm{~K}^{-1}$ ). The values of more negative entropy of activation for isopropyl fluoroformate reaction are consistent with the bimolecular nature of the rate-determining step.

Unlike the solvolyses of isopropyl chloroformate. where. in most solvents. a solvolysis-decomposition (ionization pathway) was observed. the solvolyses of isopropyl fluoroformate follow a pathway involving bimolecular attack by solvent at acyl carbon. by what is suggested that the addition step of an addition-elimination pathway is rate deternining.

\section{Experimental}

Isopropyl chloroformate in toluene $(38.56 \mathrm{~mL} .0 .038 \mathrm{~mol})$ was syringed into a three-neck flask $(250 \mathrm{~mL})$ containing dried KF (2.94 g. $0.05 \mathrm{~mol})$ and 18 -crown-6 (0.36 g. 0.0013 mol) and fitted with a Teflon stirring bar. a condenser topped by an $\mathrm{N}_{2}$ gas inlet, a septum cap, and a ground glass stopper. as described earlier ${ }^{3 i j}$ The mixture then was stirred efficiently at room temperature until FT-IR (Bio-Red FTS 6000) analysis of an aliquot indicated that no chloroformate remained $\left(\mathrm{C}=\mathrm{O}\right.$ stretch at $1729 \mathrm{~cm}^{-1}$. fluoroformate $\mathrm{C}=\mathrm{O}$ stretch at $1825 \mathrm{~cm}^{-1}$ ). After total reaction time 48 hour, the product fluoroformate was isolated directly from the reaction apparatus by simple distillation at a reaction temperature of $80-83^{\circ} \mathrm{C}$

Solvents were purified and the kinetic runs carried out as previously described. ${ }^{y, 3]}$ All runs were performed using a 
substrate concentration of $5.128 \times 10^{-3} M$ and with $5 \mathrm{~mL}$ portions removed for titration. but with $2 \mathrm{~mL}$ portions for nuns in TFE- $\mathrm{H}_{2} \mathrm{O}$ and TFE-EtOH mixtures.

Acknowledgements. This work was supported by the research fund of Hanyang University.

\section{References}

1. Winstein, S.: Grunwald. E.: Jones, H. W. J. Am. Chem. Soc. 1951. 73,2700

2. Kevill. D. N. In Adwances in Quantitative Structure-Propert! Retationships: Charton. M.. Ed.: JAI Press: Greenwich. CT. 1996: Vol. 1. pp 81-115.

3. Kevill. D. N.: Anderson. S. W. J. Org Chem. 1991. 56.1845

4. (a) Schadt. F. L.: Bentley. T. W: Schleyer. P. v. R. J. Am. Chem. Soc. 1976, 98, 7667. (b) Bentley, T. W. Llewellyn. G. Prog. Phns. Org. Chem. 1990, 17. 121

5. (a) Bentley. T. W. Carter. G. E. J. Am. Chem Soc 1982. I04. 5741. (b) Kevill. D. N.: DSouza. M. J. J. Chemt Res., Smop. 1993. 174. (c) Lomas. J. S.: D'Souza. M. J.: Kevill. D. N. J. Am. Chem. Soc. 1995, 117. 5891. (d) Kvong, J. B.: Park, B. C.: Kim. C. B.: Kevill, D. N. J. Org. Chem. 2000. 65,8051. (e) Kevill. D. N.: DSouza. M. J. J. Phis. Org. (them. 2002. 15,881.

6. Kyong. J. B.: Kim. Y. G.: Kim. D. K.: Kevill. D. N. Bull. Korean Chem. Soc. 2000. 21.662.

7. Kevill. D. N.: Kyong. J. B.: Weitl. F. L. J. Org. Chent 1990.55. 4304

8. Kevill. D. N.: Weitl. F. L. Tetratredron Lett. 1971.707.

9. Kevill D. N.: Kyong. I. B. J. Org Chem. 1992, 57. 258.

10. Kevill. D. N. D Soluza, M. I. J. Chem. Soc. Perkin Trans. 22002. 240.

11. Kvong, I. B.; Rvu, S. H. Kevill. D. N. Int. J. Mol. Sci. $2006,7$. 187

12. Kevill. D. N. In The Chemishy of the Functional Groups: The Chemishy of Acyl Halides: Patai. S.. Ed.: Wiley: New York: 1972:
Chapter 12

13. Kevill. D. N.: D'Souza. M. T. J. Org Chent 1998. 63. 2120.

14. Kevill. D. N.: D'Souza. M. J. J. Chent. Soc.. Perkin Trams. 21997. 1721 .

15. Kevill. D. N.: Miller. B. J. Org. Chem 2002. 67.7399

16. Kevill, D. N.: DSouza. M. J. J. Org. Chem. 2004. 69, 7044.

17. Kevill, D. N.: Kim. J. C.. Kyong, J. B. J. Chem. Res., Synop. 1999. 150 .

18. Swain. C. G.: Scott. C. B. J. Ant Chem. Soc. 1953. 75. 246.

19. Song. B. D.: Tencks. W. P. J. Am. Chem. Soc. 1989. M11. 8470.

20. (a) Glew. D. N.: Moelwyn-Hughes. E. A. Proc. R. Soc. London Ser A 1952, 211. 254. (b) Fells, I; Moelwyn-Hughes, E. A. d. Chem. Soc. 1959, 398. (c) Bathgate, R. H.; Moelwyn-Hughes, E. A. J. Am Chent Soc. 1959.2642 (d) Robertson. R. E. Prog Phos. Org. Chent 1967. 4.213.

21. Bunton. C. A. Nucleophinic Substintion at a Satmated Carbon Atom: Elsevier: Amsterdam, The Netherlands, 1963: pp 160-162

22. (a) Wiberg. K. B.: Hadad C. M.: Rablen. P. R.: Cioslowski. J. J Am. Chem. Soc. 1992. 114,8641. (b) Wiberg. K. B.; Rablen. P. R. J. Org. Chent 1998. 63.3722.

23. Kivinen. A. In The Chemistry of Acv Haldes: Patai. S.. Ed. Interscience: New York. 1972: pp 198-200

24. Queen, A. Can. J. Chem 1967, 45,1619

25. Yew. K. H.: Koh, H. J.: Lee. H. W.: Lee. I. J. Chem Soc. Pakin Trans. 2 1995. 2263.

26. Koo. I. S.: Yang. K.: Kang. K.: Lee. I. Bull Korean Chen. Soc. 1988. 19.968

27. Ryu. Z. H.: Shin. S. H.: Lee. T. P.: Lim. G. T.: Bentley. T. W. $J$ Chem. Soc. Perkin Trans. 22002, 1283

28. Oh. Y. H.; Jang. G. G.; Lim, G. T; Ryu, Z. H. Bull Korean Chem. Soc. $2002,23,1083$

29. Orlov, S. I.: Chimishkyan, A. L.: Grabarnik. M. S. J. Org Chem. LSSR (Engl. Tranl.) 1983. 19.1981.

30. (a) Lorca. A. A.: Malfroot. T.: Senet. . . P. Lhited States Patent Application Pub. 2003. 0120103A1. Tun. 26. (b) Cuomo. T. Olofson. R. A. J. Org. Chem. 1979, 44, 1016

31. Queen, A.: Nour. T. A. J. Chem. Soc. Pakin Trans. 2 1976, 935. 